\title{
Role of Tissue Glue in Overlay Tympanoplasty vs Conventional Overlay Method
}

\author{
Surendra V Pimparkar ${ }^{1}$, Ashwani Sethi $^{2},{\text { Avinash } \text { Das }^{3}, \text { Himanshu joshi }}^{4}$
}

\begin{abstract}
Purpose: The purpose of this research is to study the role of tissue glue (TISSEL) in overlay tympanoplasty when compared with the conventional overlay method.

Study design: A prospective randomized comparative study was carried out at the ENT department of Base Hospital, Delhi, in which 60 patients with dry central perforation underwent overlay tympanoplasty. Out of these, 30 underwent conventional overlay tympanoplasty (control) and in the rest of the 30, overlay tympanoplasty was done with the use of tissue glue (cases).

Results: Graft take-up rate in control is $90 \%$ and in cases $96.7 \%(p>0.05)$. Hearing improvement within $20 \mathrm{~dB}$ of A-B gap (at 03 months) in control is 86.70 and $96.70 \%$ in cases ( $p>0.05$ ). Early hearing improvement (at 6 weeks) in cases was better when compared with the control $(p<0.05)$. The complication rate in cases is $10 \%$ with residual perforation in 01 patient, while that in control is $16.66 \%$ with residual perforation in 03 patients $(p>0.05)$.

Conclusion: Graft take-up rate in hearing improvement was found to be better in overlay tympanoplasty with the use of tissue glue when compared with the conventional method with no statistically significant difference. The only significant advantage with the TISSEL group was found to be an early hearing improvement at 6 weeks. Tissue glue (TISSEL) was found to be safe and effective.

Keywords: Fibrin glue, Overlay, TISSEL, Tissue glue, Tympanoplasty.

Journal of Medical Academics (2020): 10.5005/jp-journals-10070-0058
\end{abstract}

\section{INTRODUCTION}

Tympanoplasty is an operation to "eradicate the disease in the middle ear and to reconstruct the hearing mechanism, without mastoid surgery, with or without tympanic membrane grafting". Thus, it is designed to close the perforation of the tympanic membrane and also deals with middle ear pathology. ${ }^{1}$ There is a wide range of techniques of tympanoplasty that are described in the literature and these include the underlay technique and overlay technique. ${ }^{2}$

During the past 2-3 decades, tissue adhesives have gained popularity in various surgical procedures including otolaryngology surgery, ${ }^{3}$ micro-neuronal repair, ${ }^{4}$ and craniofacial surgery. ${ }^{5}$ The most commonly used adhesive is fibrin glue which is used to control bleeding, to adhere tissue together, and to seal tissue defects. ${ }^{6}$ Fibrin glue can be autogenous or allogenous. Autogenous fibrin glue is prepared from patients' own platelet-rich plasma or by mixing concentrated fibrinogen solutions with thrombin. ${ }^{7}$ Allogenous fibrin glue is commercially available as TISSEL/RELISEAL/ EVICEL. We used TISSEL in our study. It is prepared by mixing the TISSEL-aprotinin solution with thrombin-calcium chloride solution before surgery.

Large numbers of studies have been carried out to study the role of tissue glue in tympanoplasty by underlay technique and to compare overlay vs underlay techniques of tympanoplasty. However, studies comparing the role of tissue glue in overlay tympanoplasty and comparing it with the conventional method of an overlay is rare in literature. Thus, this study was performed and this study aims to analyze the success rate in terms of graft take-up rate and hearing improvement and to assess the advantages and disadvantages associated with the use of tissue
1,2Department of ENT, Army College of Medical Sciences, Base Hospital, New Delhi, India

${ }^{3}$ Department of Otorhinolaryngology, Army College of Medical Sciences, Base Hospital, New Delhi, India

${ }^{4}$ Department of ENT, Base Hospital Delhi Cant, New Delhi, India

Corresponding Author: Ashwani Sethi, Department of ENT, Army College of Medical Sciences, Base Hospital, New Delhi, India, e-mail: dr_sethi@rediffmail.com

How to cite this article: Pimparkar SV, Sethi A, Das A, et al. Role of Tissue Glue in Overlay Tympanoplasty vs Conventional Overlay Method. J Med Acad 2020;3(2):33-37.

Source of support: Nil

Conflict of interest: None

glue in overlay tympanoplasty vs the conventional technique of overlay tympanoplasty.

\section{Materials and Methods}

Sixty patients belonging to different geographical areas of India presenting to the department of ENT-HNS of Base Hospital, Delhi Cantt with COM mucosal inactive disease were selected for the study after taking into consideration the inclusion and exclusion criteria. Patients evaluated and operated on from April 2015 to April 2017 are addressed in this study.

\section{Inclusion Criteria}

(a) Chronic otitis media-mucosal inactive type with dry central perforation for at least 03 months. (b) Age between 16 and 50 years. (c) Both males and females. 


\section{Exclusion Criteria}

(a) All acute otitis media. (b) Chronic otitis media squamous type. (c) Chronic otitis media mucosal active or those with suspected ossicular discontinuity ( $A-B$ gap $>45 \mathrm{~dB}$ ) as a result of the disease process. (d) Any other associated condition like otosclerosis, tympanosclerosis, adhesive otitis media, congenital hearing disorder, COM with mixed or sensory neural hearing loss (SNHL). Serous otitis media. Chronic otitis externa. (e) Systemic diseases: diabetes mellitus, tuberculosis, bleeding disorders, clotting disorders, hypertension, and ischemic heart disease. (f) Intracranial and intratemporal complications of chronic otitis media.

Patients were selected for surgery, i.e., overlay tympanoplasty after thorough screening. Patients were randomly allocated into the experimental/case group (overlay tympanoplasty with TISSEL) and control group (overlay tympanoplasty by conventional method). The demographic characteristic of these groups is summarized in Table 1. There is no significant difference found between age and sex, side of ear operated in both the group. The mean age of the patient in the control group is 32 years and in cases 31 years. All patients were free from coagulation disorder, any infectious disease, and were operated on by the same surgeon in the ENT department of Base Hospital, Delhi over 24 months. The study was approved by the ethics committee of Base Hospital, Delhi and informed consent was taken from each patient before surgery.

\section{Preparation and Reconstitution of TISSEL}

Each TISSEL kit consists of (Fig. 1) (a) one blue vial containing sealer protein concentrate lyophilized, (b) one blue vial containing synthetic aprotinin solution, (c) one black vial containing calcium chloride solution, (d) one black vial containing human thrombin lyophilized, (e) one kit for reconstitution and application. Sealer protein solution (first component) is prepared by dissolving (a) and (b). Then, the vial is placed in the stirring well of FIBRINOTHERM device which maintains a constant temperature of $37^{\circ} \mathrm{C}$ and is stirred until complete dissolution of particles (Fig. 2). Thrombin solution (second component) is prepared by dissolving (c) and

Table 1: Demographic characteristics of the study group

\begin{tabular}{llll}
\hline & $\begin{array}{l}\text { Mean age } \\
\text { (years) }\end{array}$ & Male & Female \\
\hline Control & 32.17 & 16 & 14 \\
Case (TISSEL) & 30.97 & 17 & 13 \\
\hline
\end{tabular}

(d). The dissolved solution is swirled briefly and warmed using the FIBRINOTHERM device. Before administration, TISSEL is warmed to 33 to $37^{\circ} \mathrm{C}$. Both these solutions are taken into a separate syringe and with help of a DUPLOJET syringe in which it gets mixed applied to the desired part with applicator by using drop technique.

\section{Surgical Method}

After a thorough screening, clinical examination, investigation, and PAC fitness, the patient is taken up for surgery. Local infiltration is given with $2 \%$ lignocaine and 1:80,000 adrenaline as per Plester's technique. A postaural approach was used in both groups. A lateral circumferential incision is given $>5 \mathrm{~mm}$ lateral to the annulus at 11-o' clock position and continues round till 1-o'clock position. A large tympanomeatal flap is elevated down to the annulus and then all the epithelium from the drum remnant, as well as from the malleus handle, is elevated (Fig. 3). In the control group, the middle ear cavity is packed with gelfoam to support the graft medially. The temporalis fascia is placed on the annulus, on the malleus handle and its short process, on the Shrapnel's membrane region, and on the ear canal bone. Then, the flap is returned to its original position and fixed with gelfoam balls, initially at the anterior tympanomeatal angle and then at other margins. Finally, a large gelfoam ball is placed on the umbo to prevent lateralization of the graft. In the experimental/case group, after placing the graft as mentioned earlier, few drops of TISSEL solution are applied with a DUPLOTIP

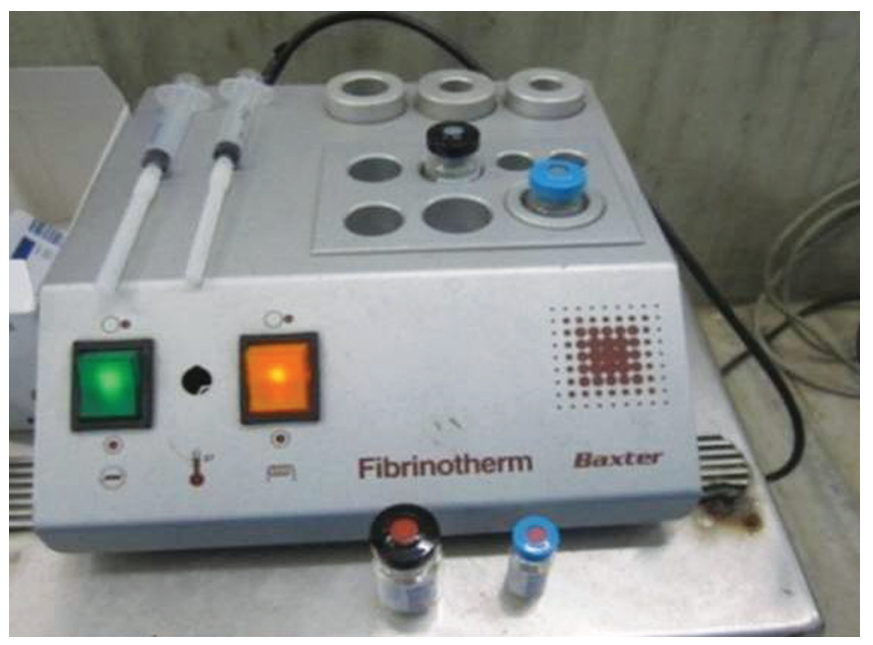

Fig. 2: Fibrinotherm device

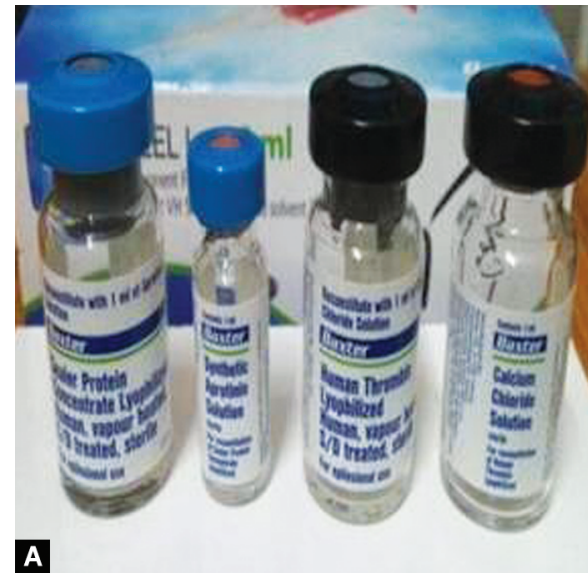

Figs $1 \mathrm{~A}$ to $\mathrm{C}$ : TISSEL kit
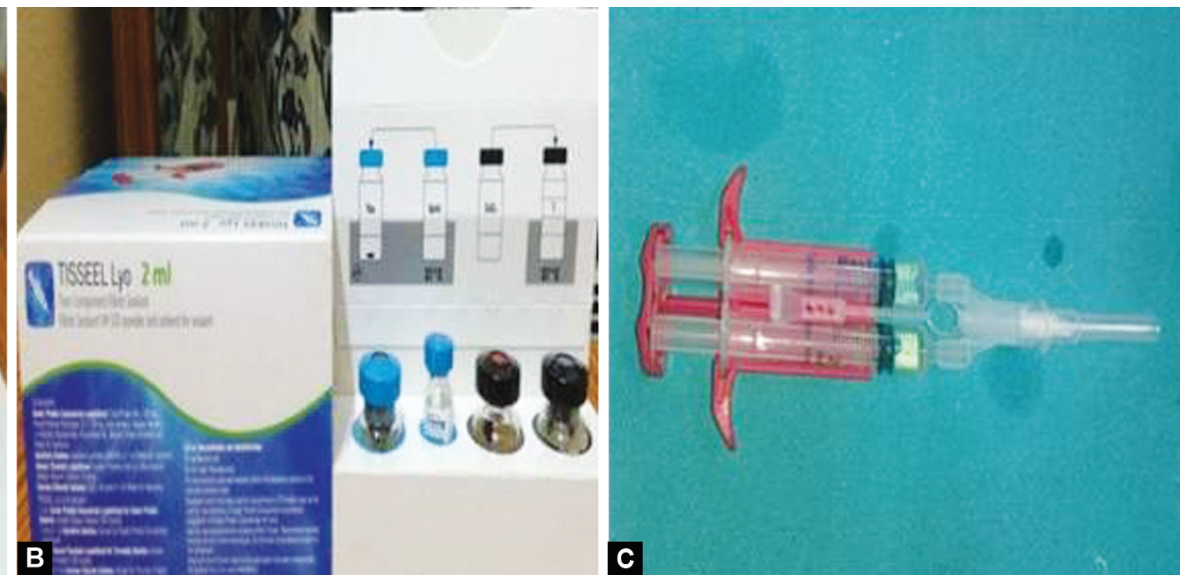
syringe over the margins of the graft starting from the anterior tympanomeatal angle (Fig. 4). Tympanomeatal flap is returned to its position. Gelfoam is neither used to fix the margins in this technique nor used for packing the middle ear cavity. In both the techniques, however, BIPP soaked gel foams are loosely packed into the EAC and BIPP soaked ribbon gauze is placed in EAC.

Patients are monitored intraoperatively and postoperatively for any complications. Patients were examined serially by otoscopy, otomicroscopy during the postoperative follow-up period at 06 weeks and 03 months. Hearing evaluation by tuning fork test (TFTs), free field hearing (FFH), and pure tone audiometry (PTA) was carried out at 03 months postoperatively. The operation was considered successful if the patient has intact and non-displaced TM at 06 weeks and 03 months. Hearing improvement was assessed by using standard guidelines of Glassgow benefit plot $^{8}$ and A-B gap at 03 months (Fig. 5).

The comparison of study outcome factors between study groups was done using independent two-sample $t$ test or Pearson chi-square/ANOVA, Fisher's exact test, post hoc test as appropriate. Multiple logistic regression analysis was used to assess the independent effect of the two different methods on the study outcome. The Statistical software namely SAS 9.2, SPSS 16.0, Stata 10.1, MedCalc 9.0.1, Systat 12.0, and R environment ver.2.11.1 was used for the analysis of the data, and Microsoft Word and Excel have been used to generate graphs, tables, etc.

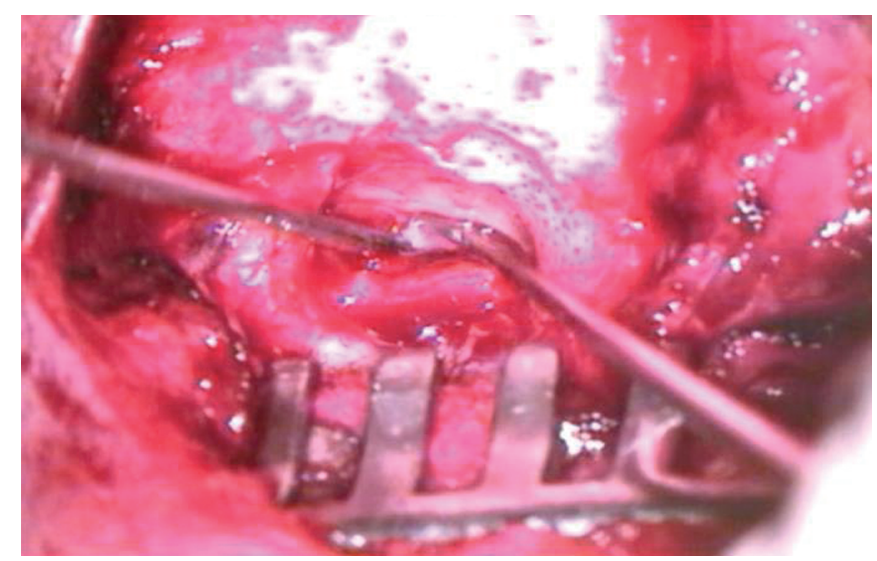

Fig. 3: Elevating epithelium

\section{Results}

In our study in the control group, the graft take-up rate is $90 \%$ and there is a significant hearing outcome with $A-B$ gap closure within $10 \mathrm{~dB}$ in $66.70 \%$ and within $20 \mathrm{~dB}$ in $86.70 \%$ of patients, while $83.4 \%$ of patients falling in a,b category of Glasgow benefit plot, suggestive of clinically significant hearing benefit. Similarly, the graft take-up rate is $96.7 \%$ in the case/experimental group and significant hearing outcome with A-B gap closure within $10 \mathrm{~dB}$ in $70 \%$, within $20 \mathrm{~dB}$ in $96.70 \%$ of patients (Fig. 6), while $86.6 \%$ of patients falling in a,b category of Glasgow benefit plot. However, there was no significant difference between these two methods in terms of graft take-up rate and hearing outcome at 03 months ( $p$ value $>0.05$ ). The only significant advantage with the use of TISSEL was found to be an early hearing improvement (at 06 weeks) when compared with the control group ( $p$ value $<0.05$ ) (Fig. 7). There was no statistically significant difference $(p>0.05)$ for age and gender profile between the two groups. Similarly, no significant difference was between hearing outcomes and different age groups ( $p$ value 0.426 ) and between males and females ( $p$ value 0.732 ).

The complication rate in cases is $10 \%$ with residual perforation in 01, EAC infection in 01, and SNHL in 01 patient while that in control is $16.66 \%$ with residual perforation in 03 , EAC infection in 01 , and anterior blunting in 01 patient $(p>0.05)$.

\section{Discussion}

The study showed a higher graft take-up rate, increased hearing outcome, and less lateralization (anterior blunting) in overlay tympanoplasty with tissue glue. Early hearing improvement at 06 weeks was the only statistically significant advantage. TISSEL was found to be safe and effective without any risk of infectious disease, hypersensitivity.

Various studies have been carried out to study graft take-up rate and hearing improvement in overlay tympanoplasty by the conventional method (Table 2).

In our study, graft take-up rate in the control group is $90 \%$ and in the TISSEL group is $96.7 \%$ which is at par with other studies of overlay tympanoplasty as mentioned above. Though there is no significant difference between these two methods ( $p$ value $>0.05$ ) graft take-up rate was a little higher in the TISSEL group.
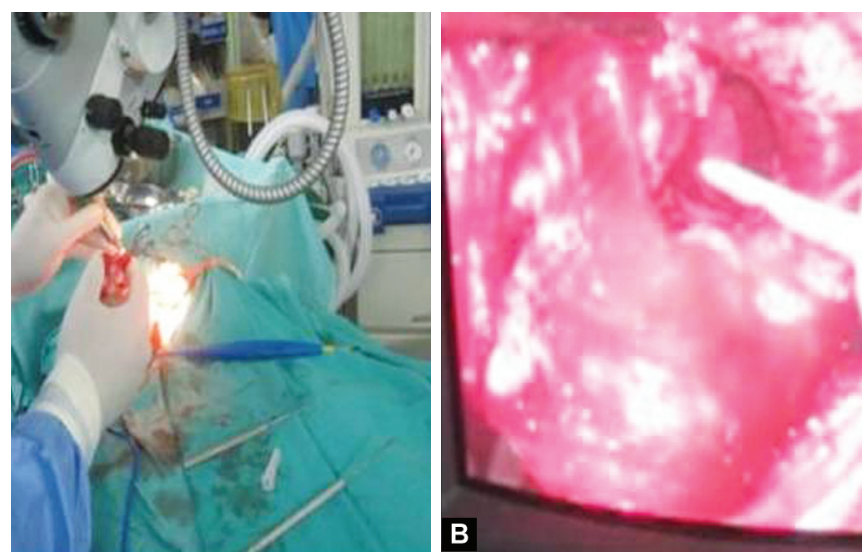

Figs 4A and B: Application of TISSEL on edges 

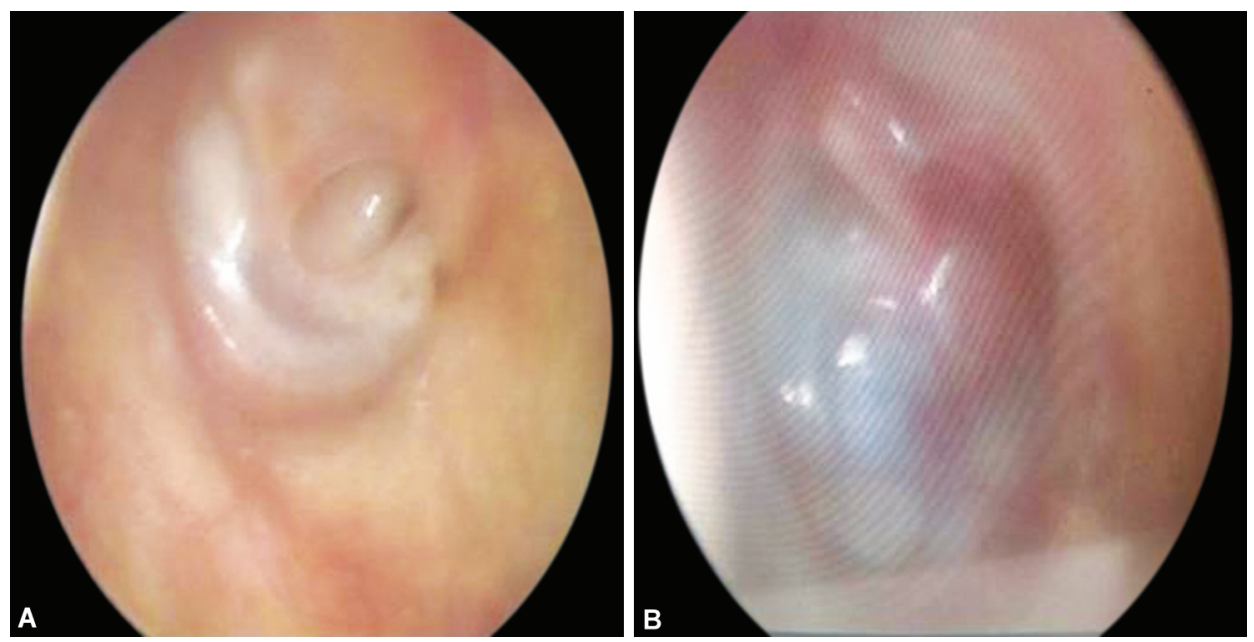

Figs 5A and B: Preoperative and postoperative tympanic membrane

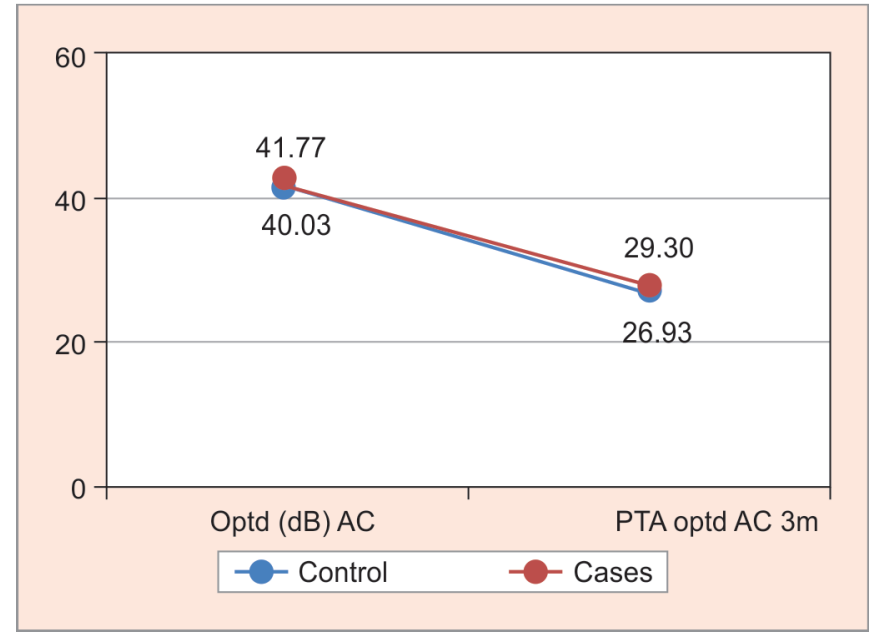

Fig. 6: XXX

Table 2: Studies on overlay tympanoplasty

\begin{tabular}{|c|c|c|c|c|}
\hline Sl. no. & Study & Technique & $\begin{array}{l}\text { Graft take- } \\
\text { up rate (\%) }\end{array}$ & Hearing outcome \\
\hline 1 & Doyle et al. ${ }^{9}$ & 52 overlay & 64 & $\begin{array}{l}\text { A-B gap within } \\
15 \mathrm{~dB} \text { in } 27 \%\end{array}$ \\
\hline 2 & $\begin{array}{l}\text { Sheehy and } \\
\text { Anderson }^{10}\end{array}$ & 472 overlay & 97 & $\begin{array}{l}\text { A-B gap within } \\
10 \mathrm{~dB} \text { in } 80 \%\end{array}$ \\
\hline 3 & Glasscock $^{11}$ & Overlay & 91 & \\
\hline 4 & Rizer $^{12}$ & 158 overlay & 96.5 & $\begin{array}{l}\text { A-B gap within } \\
10 \mathrm{~dB} \text { in } 80.4 \%\end{array}$ \\
\hline 6 & $\begin{array}{l}\text { Singh et } \\
\text { al. }^{13}\end{array}$ & 30 overlay & 93.3 & \\
\hline
\end{tabular}

In a study by Doyle et al. ${ }^{9}$ in which he compared 52 ears reconstructed with the overlay technique to 79 ears reconstructed with the underlay technique, the failure rate was quite high with an overall re-perforation rate of $36 \%$ for the overlay technique vs $14 \%$ for the underlay technique. One thing to note is that all the tympanoplasties performed in Doyle's study were done through an end aural approach. In our study, we performed all surgeries through a postaural approach, thus giving us a high success rate.

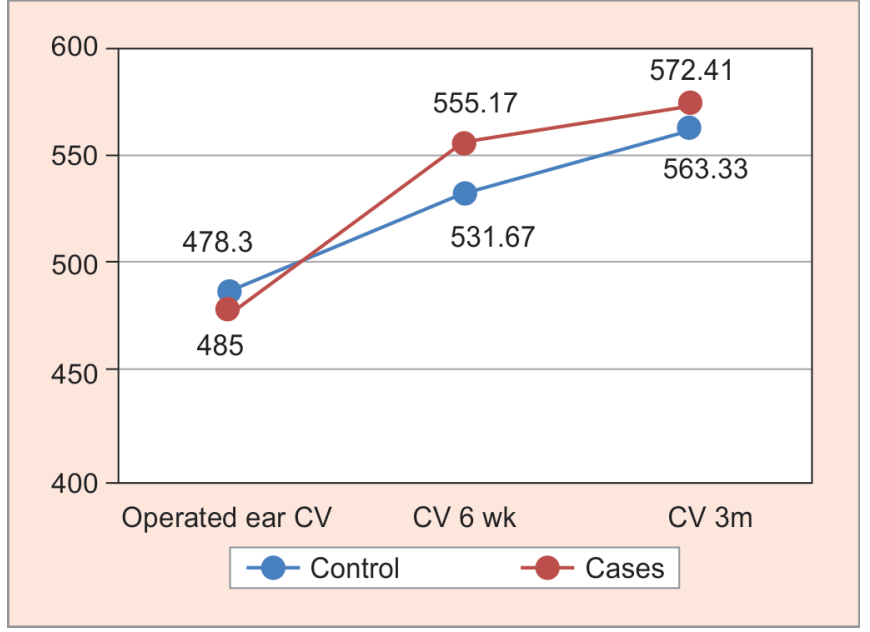

Fig. 7: XXX

In 1977, Tos and Everberg ${ }^{14}$ performed a controlled randomized prospective study on autogenous fibrin glue comparing Everberg's method of fibrin glue graft fixation with Tos's method of Gelfoam fixation. In a study of Tos and Everberg, 29 patients with dry perforation, temporalis fascia was glued with tissue seal. In 30 patients, the fascia was fixed with Gelfoam balls. No significant differences in intake rate were found between these two methods. Another advantage of this technique is rapid improvement of patient hearing after removing the external ear canal pack. ${ }^{15}$ Similarly, in our study, there was no significant difference in graft take-up rate, however, at 06 weeks, there was a significant hearing improvement in cases when compared with the control group ( $p$ value $<0.05$ ). However, no significant difference at 03 months suggestive of early hearing improvement in cases with the use of fibrin glues (TISSEL).

Commercially available tissue glues were introduced into tympanoplasty by Panis et al. in $1979^{16}$ with favorable results for graft take rate. In 20 patients with recurrent perforation of TM, tympanoplasty was done and closure was attempted with fibrin tissue adhesive and in 15 it was successful. The fibrin glue was used in 10 cases of myringoplasty. Seven cases of myringoplasty were done as classical underlay technique. The graft was placed lateral to the handle of the malleus and fibrin glue was applied at the margin 
of the tympanomeatal flap after it was repositioned. On follow-up, it was found that graft was taken up in 9 out of 10 cases. There was neither lateralization nor medialization of the graft. Pure tone audiometry showed improvement in the air-bone gap. ${ }^{17}$

In our study, we used commercially available fibrin glue TISSEL with the DUPLOJET technique by drop method. Thus, fibrin glue gets prepared while injecting and is directly applied on graft margins, avoiding unnecessary gluing at other sites. There is no study in English literature comparing the use of allogenous tissue glue/TISSEL in overlay tympanoplasty with the conventional overlay method. In both the methods in our study (i.e., with or without TISSEL), graft take-up rate and hearing improvement were significant. Results were better in TISSEL/case group but not statistically significant.

Sheehy and Anderson ${ }^{10}$ reviewed 472 cases of overlay tympanoplasty. $1.3 \%$ of cases were complicated by anterior blunting and lateralization. The largest study to date comparing overlay to underlay grafting was performed by Rizer. ${ }^{12}$ Complications were seen in $7.8 \%$ of the underlay group which included infection and worsened hearing. In the overlay group, $8.9 \%$ experienced complications which included infection, worsened hearing, and lateralization of the TM (one case). Singh et al. ${ }^{13}$ performed a comparative study of the underlay and overlay technique of myringoplasty in large and subtotal perforations of TM on 60 patients ( 30 underlays vs 30 overlays) with fewer minor complications (6.6 vs $33.3 \%$ ).

Plasma-derived products are potential virus transmitters. Safety of plasma-derived products with respect to HIV, HBV, and $\mathrm{HCV}$ is now well established even when a single method of virus inactivation is used. There are certain risks associated with the use of FG. Thromboembolic complications and DIC can occur if a sealant is unintentionally administered intravascularly. Certain fibrin glue (TISSEL) contains aprotinin, an antifibrinolytic agent. It carries a risk of hypersensitivity reactions, but the reported incidence of hypersensitivity reaction is very rare $(0.5 / 100,000$ applications). In our study, the complication rates are on par with other world literature. In the control group, it was found to be $16.66 \%$ with secondary infection of EAC in one case, anterior blunting in one case, and residual perforation in three cases. The complication rate in the TISSEL group was 10\% with secondary infection in EAC in one case, graft lateralization in one case, and profound SNHL in one case. However, the exact reason for profound SNHL in one case cannot be identified.

No other complications related to TISSEL like hypersensitivity reactions, thromboembolic events, or infectious diseases like HIV, $\mathrm{HCV}$, and HBV were found in our study suggesting the good safety profile of TISSEL.

\section{Conclusion}

In our study, both the techniques (i.e., overlay tympanoplasty with or without TISSEL) were having a high success rate and improved hearing outcome. Graft take-up rate and hearing outcome were better in patients who underwent overlay tympanoplasty with TISSEL when compared with the conventional overlay method but, the difference was not statistically significant. One significant advantage of using TISSEL was found to be an early hearing improvement (at 6 weeks) when compared with the control group. In our study, the use of TISSEL was found to be safe and effective. Except for one case of profound SNHL (cause for which cannot be directly attributed to the use of TISSEL), there were no major complications like hypersensitivity reaction, hepatitis B, C, or HIV. One of the benefits of TISSEL was found to be the prevention of anterior blunting in overlay tympanoplasty, but to significantly relate this with TISSEL will need further study with larger sample size.

\section{References}

1. Frootko NJ. Reconstruction of middle ear. In: Kerr AG, Booth JB, ed. Scott-Brown's Otolaryngology. 6th edn, Great Britain: Butterworth Heinmann; 1997. pp. 1-6.

2. House WF. Myringoplasty. AMA Arch Otolaryngol 1960;71:399-404. DOI: 10.1001/archotol.1960.03770030041009.

3. Staidl $O$. Healing of wounds and scar formation under the coagulation factor XII. Arch Otorhinolaryngol 1979;222(4):41-45.

4. Kuderna H, RedI IL, Dinges IL. The repair of severed peripheral nerves by means of fibrin seal. Clinical experience and results. Eur Surg Res 1979;11:98-99.

5. Marchac D, Renier D. Fibrin glue in craniofacial surgery. J Craniofac Surg 1990;1(1):2-4. DOI: 10.1097/00001665-199001000-00008.

6. Schneider G. Tissue adhesives in otorhinolaryngology. GMS Curr Top Otorhinolaryngol Head Neck Surg 2009;9 http://www.egms.de/ static/de/journals/cto/2011-8/cto000053.shtml.

7. Durham LH, Wilatt DJ, Yung MW, et al. A method of preparation of fibrin glue. J Laryngol Otol 1987;101(11):1182-1186. DOI: 10.1017/ S0022215100103469.

8. Browning GG, Gatehouse S, Swan IR. The glassgow benefit plot: a new method of reporting benefits from middle ear surgery. Laryngoscope 1991;101(2):180-185. DOI: 10.1288/00005537-199102000-00014.

9. Doyle PJ, Schleuning AJ, Echevarria J. Tympanoplasty: should grafts be placed medial or lateral to the tympanic membrane. Laryngoscope 1972;82(8):1425-1430. DOI: 10.1288/00005537-197208000-00005.

10. Sheehy JL, Anderson RG. Myringoplasty. A review of 472 cases. Ann Oto Rhinol Laryngol 1980;89(4 pt 1):331-334. DOl: 10.1177/000348948008900407.

11. Glasscock 3rd ME. Tympanic membrane grafting with fascia: Overlay vs underlay technique. Laryngoscope 1973;83(5):754-770. DOI: 10.1288/00005537-197305000-00011.

12. Rizer FM. Overlay vs underlay tympanoplasty. Part II: the study. Laryngosscope 1997;107(12 pt 2):26-36. DOI: 10.1097/00005537199712001-00002.

13. Singh M, Rai A, Bandyopadhyay S, et al. Comparative study of underlay and overlay technique of myringoplasty in large and subtotal perforations of the tympanic membrane. J Laryngol Otol 2003;117(6):444-448. DOI: 10.1258/002221503321892262.

14. Tos M, Everberg G, Henrichsen J. How I do it-otology and neurotology, a specific issue and its solution autologous tissue seal in myringoplasty. Laryngoscope 1987;97(3 pt 1):370-371.

15. Ghayasi S, Seyed Tutoonchi SJ. Tympanoplasty without use of gelfoam in the middle ear. Iranian J Otorhinolaryngol 2008;20(52):65-70.

16. Panis R, Rettinger G. Closure of recurrent perforations of the tympanic membrane. HNO 1979;27(12):413-415.

17. Arjunan K, Thiagarajan B, Narsimhan S. Role of tissue adhesive in otorhinolaryngology. Ototlaryngol Online J 2012;2(3):42. DOI: 10.5455/jorl.51-1335890250. http://www.jorl.net/otolaryngology/ role-of-tissue-adhesive-in-otorhinolaryngology.pdf. 